\title{
Welcoming Ain't Belonging: A Case Study that Explores How Two-year Predominantly White Colleges Can Foster an Environment of Validation and Mattering for Men of Color
}

\author{
Patrick Turner ${ }^{1} \&$ Efren Miranda Zepeda ${ }^{2}$ \\ ${ }^{1}$ First Year Initiatives, New Mexico State University, Las Cruces, New Mexico \\ ${ }^{2}$ College of Education, New Mexico State University, Las Cruces, New Mexico \\ Correspondence: Patrick Turner, First Year Initiatives, New Mexico State University, New Mexico. Tel: \\ 576-646-7926. E-mail: peturner@nmsu.edu
}

Received: February 2, 2021

doi:10.5539/hes.v11n2p127

Accepted: March 21, $2021 \quad$ Online Published: March 28, 2021

URL: https://doi.org/10.5539/hes.v11n2p127

\begin{abstract}
The qualitative case study explored the factors that foster an atmosphere of belonging for men of color (MOC) attending a 2-year Predominantly White Institution. The pressing issue is that PWI colleges make the erroneous assumption that an extension or invitation of welcome is the same as fostering a sense of belonging for men of color (MOC). This led colleges to construct policies and practices that do not intentionally and deliberately create an atmosphere where MOC feel valued, validated, and visible. According to Maestas, Vaquera, and Zehr (2007), fostering a sense of belonging is paramount to the retention and graduation of students of color. The study surfaced three central themes: (a) experiencing an atmosphere of welcome, (b) desire for cultural representation and celebration (c) importance of Diversity, Equity and Inclusion (DEI) training. Though most colleges boast of creating a sense of belonging, the National Center for Education Statistics (2019) reports 25\% of men of color graduate from a community college within $150 \%$ or three-years of normal time. Additionally, the Community College Survey of Men (CCSM) reports a lack of validation, engagement, and high attrition rate for men of color attending these institutions (Harris \& Wood, 2013). This can be problematic considering the majority of men of color began their academic journey by attending 2-year colleges. Community and 2-year colleges are critical to the educational system and positioned to improve access and equity for students of color, particularly males (Bailey, Jaggars, \& Jenkins, 2015).
\end{abstract}

Keywords: male students, first year, belonging, students of color, retention, graduation

\section{Introduction}

\subsection{Introduction of Problem}

Research has shown that students of color (e.g., Blacks, American Indians, and Hispanics) are underrepresented and underserved in postsecondary education, which leads to an increase in the opportunity gap and a decrease in social mobility advancement (American Council on Education, 2020; Museus et al., 2018). Over the last 20 years, the landscape of the postsecondary education system in the U.S. has posed both challenges and opportunities to the educational attainment and support provided to a growing diverse population of students (Grawe, 2021; American Council on Education, 2020). Along with increased public scrutiny concerning the cost-benefit of a college education, institutions struggle to ensure equity in access and support to a changing demographics of learners, particularly students of color and marginalized populations (Kuh, Ikenberry \& Jankowski, 2015; Arum \& Roksa, 2011). Among those challenges is the ability to foster a college environment that promotes a sense of belonging through intentional and orchestrated efforts. This effort becomes even more important for students of color attending Predominantly White Institutions (PWI), who are less likely to feel culturally validated, understood, and supported (Banks \& Dohy, 2019; Museus et al., 2018). These students experience high levels of alienation and isolation when disconnected from culturally reinforced and validated identities in an atmosphere that does not mirror their communities (Banks \& Dohy, 2019; Museus et al., 2018). Students of color experience a lack of belonging at predominantly white institutions are forced to navigate acts of racism and microaggressive behavior from both peers and instructors on a daily basis (Banks \& Dohy, 2019). Unlike other large companies and organizations, higher education does not offer extensive training to help 
students adjust to the academic and social environment (Hunter, 2006). A challenging college transition can negatively affect institutional measures and outcomes such as student retention, persistence, and graduation (Strayhorn, 2012).

Public Two-Year Colleges struggle to construct programs and services that adequately engage and support men of color (Felix \& Gonzalez, 2020; Kniess, Buschlen \& Chang, 2020; Seidman, 2012), particularly, institutions that are categorized as predominantly white institutions (PWI). Compared to other racial and ethnic groups, men of color have the lowest rate of college retention, persistence, and degree attainment; a fact attributed to educational, gender, and societal inequities (Felix \& Gonzalez, 2020). Often these institutions lack adequate resources or a comprehensive understanding of the background and experiences of men of color, which either results in poor program planning, inadequate support, or avoidance of the issue (Briscoe, Jones \& Hatch-Tocaimaza, 2020; Seidman, 2012). Though a small number of males do persevere toward a successful college matriculation, colleges cannot claim successful outcomes in serving this marginalized and invisible population of students (Guillory \& Wolverton, 2008). These men persist not because of, but despite the pressing conditions.

The majority of men of Color (MOC) begin their academic journey at a public two-year college (Postsecondary National Policy Institute, 2019). During the academic year of 2015-16, 62\% of males enrolled in community colleges, in which the majority identified as a male of color (Postsecondary National Policy Institute, 2019). A recent report by the American Council on Education noted that in 2015-16, 64\%-American Indian or Alaska native, $47 \%$-Black, 57\% -Hispanic and 47\%- Native Hawaiian or other Pacific Islander males attended a public two-year institution, compared to $43 \%$ white males. However, the large enrollment numbers of men of color do not necessarily result in degree attainment (Seidman, 2012). According to the National Center for Education Statistics (2019) approximately, 33\% of white males attending 2-year college students graduate within 3 years or 150 percent of normal time, compared to only $22 \%$ for Blacks, $26 \%$ for Hispanics and $27 \%$ American Indian/Alaska Native categorized as first-time, full-time degree or certificate-seeking students. Though a large percent of men of color begin their academic journey through public two-year institutions, only a quarter complete a credential within 3 years (NCES, 2019).

A quality education for MOC is more important than ever since most current and future jobs will require highly educated and skilled workers (Institute for Higher Education Policy, 2013). Additionally, the workforce benefits in ways of innovation, productivity, creativity, and competitiveness with racially and ethnically diverse employees (American Council on Education, 2020). An education becomes essential for a population considered as living in a third America, forced to exist outside the margins of a political, economic, and social system (Institute for Higher Education Policy, 2013). The educational journey and pipeline for men of color remains a major crisis when looking at the high-risk of drop or stop out and the low rate of retention. A precursor to constructing intentional efforts and interventions for men of color begins with a comprehensive understanding of the existing systemic and structural inequities of the institution (Briscoe, Jones \& Hatch-Tocaimaza, 2020).

\subsection{Literature Review}

The report, The Educational Experience of Young Men of Color, published by the College Board (Lee \& Ransom, 2011) postulated that for the U.S to hold the highest levels of degree attainment again, about 13.4 million college degrees would need to be ensured by 2020. This poses a challenge to the U.S education system for various reasons. First, a dramatic shift in how colleges educate and support students need to occur for an increasing racial and ethnically diverse population (Grawe, 2021; American Council on Education, 2020). Second, males are more likely to drop out of high school and less likely to gain access or graduate with a postsecondary degree than their female counterparts (Lee \& Ransom, 2011). Therefore an extensive examination of the educational pipeline for men of color needs to be conducted. Men of Color experience multiple barriers that prevent access to a postsecondary degree such as social, academic, familial, institutional, psychological, and economic (Institute for Higher Education Policy, 2013). Some common factors that hinder achievement for young African American, Hispanic, and Native American males include high grade-level repeat, poor academic achievement, and excessive assignment to special education programs (Lee \& Ransom, 2011).

Additionally, there exist inequities and stereotypes based on race/ethnicity and gender which is shown in the underrepresentation of young Black males in gifted programs or the lack of access of Native American males to a core academic curriculum and their overrepresentation in the prison and juvenile system. Similarly, the prominent levels of achievement ascribed to Asian American males seem to disguise the multiple issues encountered, especially those coming from countries in Southeast Asia such as Philippines, Thailand, Vietnam, and Indonesia (Lee \& Ransom, 2011). For example, Asian American and Pacific Islanders (AAPI) reported 
facing the burden of the "Model Minority Myth," the stereotype that some racial groups inherently possess an extreme high aptitude in academic areas such as Science, Technology, Engineering, and Math (STEM). The narrative and mischaracterization can result in high levels of stress, dropout, and poorly designed interventions because the concept negates individuality and differences (Lee \& Ransom, 2011).

The Institute for Higher Education Policy (2013) stated, "the greatest leak in the educational pipeline occurs between high school and college" (p.4). The main reason for such "leakage" is the high dropout rates for MOC across racial/ethnic groups (Platt, Holloman \& Watson, 2015). However, other identified factors contribute to the issue. For example, Black males have reported disengagement due to microaggression and negative stereotypes while Native American males encounter issues such as poor faculty-student interaction, low parental support, unpleasant college environment, and financial hardships (Kniess, Buschlen \& Chang, 2020). Furthermore, both groups have been noted to face elevated levels of absenteeism and suspensions due to a high level of educational disengagement (Lee \& Ransom, 2011); a disengagement connected to a lack of positive teacher-student relationships, and culturally competent school personnel, teachers and counselors, which translates into low academic expectations (Kniess, et al., 2020). Research has shown that poverty, scarcity of role models, and negative racial stereotypes are major factors that impede the academic and social success of men of color (Jr \& Ransom, 2011). Although men of color face many similar challenges, they are not a monolithic group. Cultural differences should be recognized when designing support program, activities, or interventions (Institute for Higher Education Policy, 2013).

\subsection{Sense of Belonging}

Recently, the term sense of "belonging" has been a focal point for many colleges and universities as institutions search for ways to increase student engagement, retention, persistence, and attainment, while they foster agency and psychological well-being. This is particularly true for those historically underserved and under-represented student populations such as low-income, LGBTQ+, first-generation, and students of color who often complain of not feeling safe, valued, respected, and visible. The concept of belonging is referred to as a psychological experience when an individual possesses membership to a particular community that is committed to fulfilling, supporting, and meeting the needs of the individual as well as the group. Strayhorn (2012) postulated that a sense of belonging refers to a feeling that one matters, valued, and respected by a group or organization. The outcome is a stronger student connection and commitment to the vision and mission of the organization, which in turn increases persistence and retention.

Though a sense of belonging has emerged as a key factor in having an impact on student retention and degree attainment, little research exists regarding two-year PWI institutions' understanding of this term, and in what ways belonging is operationalized. Extensive research has been conducted on sense of belonging, yet men of color remain less likely to be retained, persistent, and graduate at a Predominantly White Institutions. According to Strayhorn (2012), creating a sense of belonging is critical to the academic and social success for students of color. When there are opportunities for students to interact with faculty, staff, and peers in a positive manner, commitment, and retention rates rise while the likelihood of leaving decreases.

\subsection{You are Welcome}

To place the concept of "welcome" into context, we refer to Webster dictionary which defines the term as the act of being received with a friendly greeting or an extension of kindness or pleasantry. Darling (2018) expands on this definition by highlighting that the motives behind the gesture depend on the pleasure of the individual presence. Darling (2018) explores how the 'culture of welcome' is fostered. A culture of welcome may take many forms or modes and comes with varying degrees of intentionality and recognition. A welcoming environment may be either intentionally and personally conveyed or resulting from a generalized disposition or commitment. Regardless of the form, welcoming is deemed a negotiated process that involves varying durations, demands, and levels of commitment (Darling, 2018).

The "professionalization of welcome" illustrates how the intentional and voluntary interpersonal nature can be deemed a transactional act (Darling, 2018). For example, a welcoming environment is created out of social civility, such as a public, planned or official event or activity. Darling (2018) asserts, this type of welcome may only have a temporary effect and does not necessarily translate into a deeply rooted experience as it is less demanding, genuine, and/or personal, and more of a politically constructed expectation. In the context of higher education, ensuring that students feel welcome to the campus is to support the transition or orientation into college life.

Colleges invest thousands of dollars and campus resources each year to welcome new and returning students to campus. Typically, these events and activities vary in duration and usually a collaboration between several 
departmental units. The American Association of College Unions International reports the important role that college unions and departments play in fostering a welcoming environment with a focus to build and sustain the community spirit of the college (Rudisille, Stringer \& Thiebe, 2012). For example, the University of North Carolina- Charlotte, opened a student union a few years ago with the goal of increasing community and welcome. Similarly, the University of Tennessee-Knoxville made intentional efforts to conduct student activities and programming that required attendees, especially new students, to interact with each other at welcome week, and other orientation-related events (Rudisille, Stringer \& Thiebe, 2012). The authors postulate that regardless of the way these events are implemented, the goals remain the same: social interconnectedness and students' familiarization with the campus life.

\section{Method}

\subsection{Purpose of the Study}

The purpose of this qualitative case study was to explore the factors that foster an atmosphere of belonging for men of color (MOC) attending a 2-year Predominantly White college. The data collected for this study was a subset of a larger inquiry that posed the question, "How do Men of Color (e.g., African Americans, Hispanic Americans, and Native Americans) reflect on their first year college experience attending a Predominantly White Community College?" The hope is that the voices and narratives of these males can provide insight into the lived experience of MOC navigating a white college community with the anticipation of being valued and mattering.

Most of the existing research on MOC in community colleges relies on quantitative research to support recommendations and inform best practices. Though a quantitative approach has many advantages, the qualitative method provides a rich human experience which captures nuances that often exist between the lines of statistical numbers and figures. The qualitative approach provided participants the opportunity to place their stories in a human context of expression. Persons or groups that have been racialized or marginalized share an exclusive perspective that can only be expressed through the lived everyday experience. Only they can express the nuances and intricacies that shape their realities (Weiston-Serdan, 2017).

The sample consisted of currently enrolled first year male students for the Fall 2017 semester, a stop out student (i.e., student who did not return for the semester) and an alumnus who obtained a degree or certificate. All participants identified as men of color with a race and ethnic profile of one-African American, two-Native American, two-Hispanic and one- biracial (Native American and White). Both traditional and non-traditional males were included in the study. Ages ranged from 18-49 with various declared majors from pre-nursing to Welding \& Fabrication. Four of the males participants were married with at least two children, and worked 30-40 hours a week and five of the males served in a military branch prior to enrolling in the two-year college.

Participants answered 23 semi-structured interview questions pertaining to the academic environment, social experience, and cultural climate of the institution. One-on-one face-to-face interviews were conducted which served as the primary source of data. The data was then transcribed by REV, a professional transcription company. The wording or phrasing used by participants was documented in its exactness, which contextualizes emotions. With qualitative content and thematic analysis, text data was interpreted through a systematic process that consisted of coding to identify patterns and themes. Qualitative content analysis entailed making valid inferences, interpretations, and inductive reasoning from these factors (Creswell, 2007).

\subsection{Research Site}

The study was conducted at a small public two-year college located in the northern region known as the Western United States. The 2-year college functions independently but reports to a parent four-year institution. Institutional Review Board (IRB) approval was processed and granted by the parent university. College enrollment is roughly 1400 students with a racial profile of 90\%- White; 3\%-American Indian/Alaskan Native; 1\%-African American; 1\%-Hispanic; 0\%- Asian and 4\%- Unknown/Not Reported. The profile mirrors the broader demographics of the State. Over 28 degrees and certificates are offered at a low tuition cost which is competitive in that region. Part-time students account for $70 \%$ of enrollment, with $25 \%$ being 25 years of age or older. The majority of students enrolled come from the surrounding rural counties with only $2 \%$ out-of-state. First-Generation students account for 34\% with over $45 \%$ who are Pell eligible. The University system has struggled with low retention and persistence rates of minority students. Statewide efforts have been made to explore corrective actions and intervention programs, but the focus has been on American Indian/Alaskan Natives. Student orientation is limited to a 4-hour new incoming freshman meeting that covers registration, learning management system (LMS), and student services (e.g., Title IX, Financial Aid, Student Success Center, Accounts Payable, etc.). 


\subsection{Participant Profile}

The six male participants selected for the study represented both traditional and non-traditional students, with ages ranging from 18- 49 years. With an average age of 37, the racial make-up of the group was one-African American, two- Native Americans, three-Hispanics and one- biracial (Native American and White). Data was collected during the Fall 2017 semester that reported the classification as freshmen (4), sophomore (one stopped out) and alumni (1). Academic majors varied as did the pursuit of a degree or certificate. Most of the males (4) were married with at least one child and worked between 30-40 hours a week. Prior to enrolling in college, five of the six males enlisted in the military immediately after graduating high school. As first-generation students, four of the men signed up for the military because of limited financial options, lack of support, and family obligations or duty. Table 1 shows the demographical information of the male participants.

Table 1. Demographical Information of Male Participants

\begin{tabular}{llllll}
\hline $\begin{array}{l}\text { Number of } \\
\text { Participants }\end{array}$ & $\begin{array}{l}\text { Average } \\
\text { Age }\end{array}$ & $\begin{array}{l}\text { Grade } \\
\text { Level }\end{array}$ & Major(s) & Race & \\
\hline $\mathbf{1}$ & 32 & $\begin{array}{l}\text { Stop Out- } \\
\text { (sophomore) }\end{array}$ & Business Administration & African American (1) & \\
$\mathbf{4}$ & 35 & Freshman & $\begin{array}{l}\text { Pre-Nursing, Associate of Science } \\
\text { (AS), Welding and Fabrication, }\end{array}$ & $\begin{array}{l}\text { Biracial American (3), } \\
\text { American/White (1) }\end{array}$ & (Native \\
& & & $\begin{array}{l}\text { Computer Science } \\
\text { Trades (Diesel) }\end{array}$ & Native American (1) \\
\hline
\end{tabular}

\subsection{Data Collection Procedure and Analysis}

The data collecting and analysis phase mirrored the larger and broader study that was conducted, which explored the first year experience of men of color attending a predominantly white institution. To gain internal institution approval, a request was submitted to the Vice President of Student affairs to get directory information (i.e., name, address, phone numbers, and campus email) and recruit males that met the criteria. Institutional Service and Technology (IS \& T), Student Support Center, and Trio SSS were able to identify 11 males who met the criteria. The 11 males were emailed information about the purpose of the study, which only six responded. In person face-face interviews were scheduled for each of the participants. During the interviews, participants were provided additional information regarding the nature of the study and a consent form granting permission to be audio recorded. Interviews lasted approximately 60 minutes, which covered several academic and social factors of the first year experience, including their personal opinion on feeling safe, valued, and mattering in the culture of the college.

To adhere to FERPA regulations, no identifiable information was recorded to safeguard the privacy of the participants. All participants were assigned a label by race (i.e., AA-African American, HA-Hispanic American and NA-Native American), classification (i.e., F- freshman, S-sophomore, SO-stop out, and GD- alumni), and a digit. The qualitative analysis software NVIVO 11 and concept mapping were used to isolate patterns and themes from the data. Instances where $60 \%$ of the participants or greater expressed a particular idea or mentioned a topic was considered a theme or pattern.

\subsection{Trustworthiness}

The trustworthiness of a study is critical to the reliability, validity, and therefore the overall credibility of the findings. Creswell (2007) recommends several steps such as member checking or informant feedback to improve the accuracy and interpretation of the information provided. The Principal Investigator (PI) conducted a member check with a small subgroup (i.e., three) to confirm the honesty of the data interpretation and that the findings resonate with their experiences. Secondly, an external independent educational researcher conducted an informal assessment of the data, posed questions, and provided feedback to the principal investigator.

\section{Findings}

The qualitative study drew exclusively on in-depth interviews regarding a sense of belonging, specifically at a 2-year predominantly white college. The following section provides insight into the significant themes that emerged from the interviews. Three central themes were identified: (a) experience an atmosphere of welcome, (b) desire for cultural representation and celebration (c) importance of Diversity, Equity, and Inclusion (DEI) training to develop cultural competence and humility. First, experience an atmosphere of welcome, demonstrates that an individual can feel welcome into a space, but still struggle with fostering meaningful social connections. The importance of cultural representations and celebration illustrates the relevance of validation and visibility. 
Finally, the need and value of diversity, equity and inclusion training at all colleges, but particularly PWI was a pressing issue. These themes determined whether the men experienced a sense of welcome or belonging while attending the predominantly white two-year college located in the Western region of the U.S. (see Figure 1).

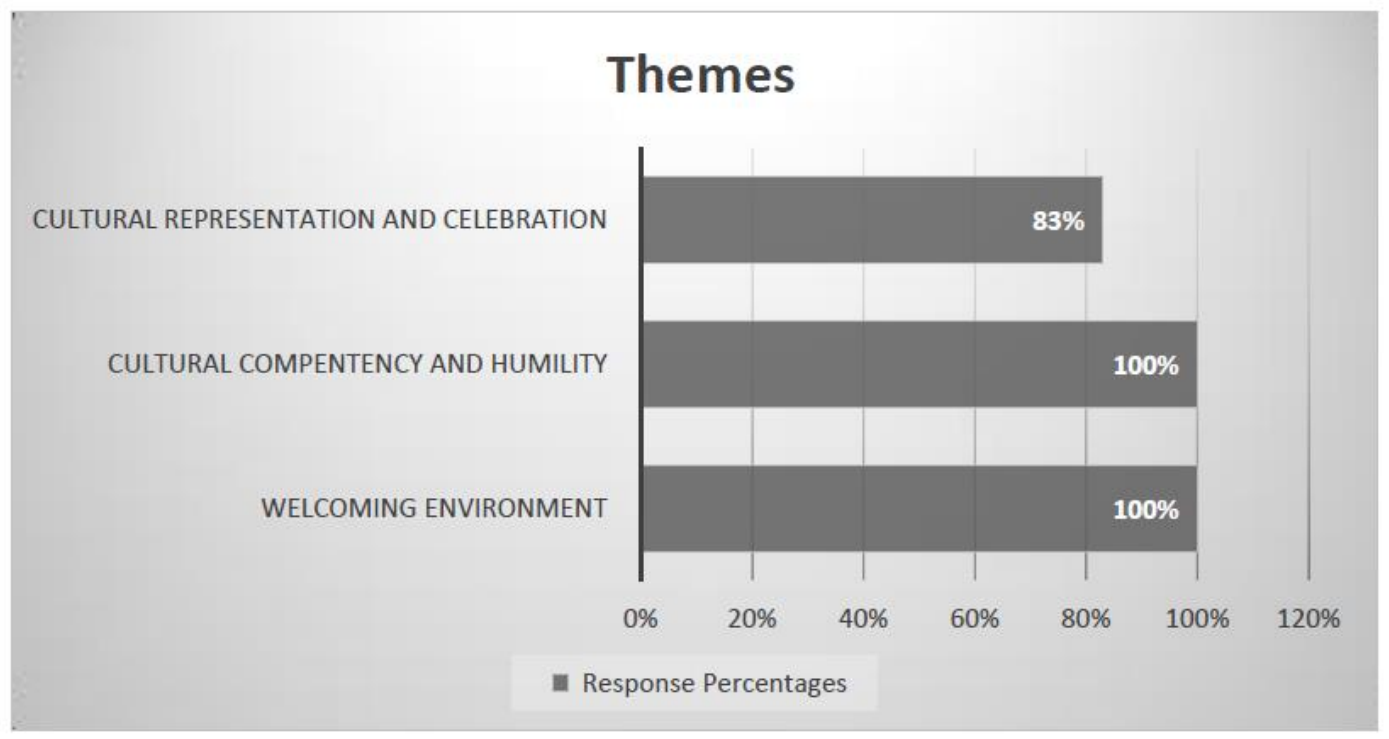

Figure 1. Emerging Themes

\section{1 "I Feel Like I am Fairly Welcome": Creating a Welcoming Environment}

The atmosphere or campus climate created by a college is critical to the overall integration of students in the academic and social community (Campbell-Whatley, Wang, \& Toms, 2015; Strayhon, 2012). Campus climate directly affects student retention, persistence, and degree attainment because it encompasses the broader experience. According to Campbell-Whatley,Wang and Toms (2015), campus climate consists of the interplay of several key factors such as people that make up the community, policies and processes, college culture, and both the individual and collective perception and expectations of membership.

Participants did feel welcome and referenced at least one specific person who treated them with kindness and respect. A few mentioned staff in TRIO SSS and campus instructors who were friendly and offered some assistance. Darling (2018) defined welcome from an etymological viewpoint. The concept of "welcome" pertains to the arrival of an individual or group which is regarded as pleasant and desired to experience. Certain actions that can convey welcome are a smile, a kind gesture of providing needed information, or other signs of friendliness.

This was supported by comments made by the participants:

- HF2: I feel like I'm fairly welcome. I didn't have any experiences where I wasn't. But, as a man of color, this is very hard for me.

- NAF1: I think it is open and welcoming, but I wouldn't say that I belong. They treat you differently. At least the Army just treated everybody equally crappy.

- NAGrad5: I would say they ... I had the ability to talk about race, especially when they would talk about the poor house, and the reservations, especially in the psychology and sociology classes. But I think they already had their minds made up of what the answers should be. So even though they let me talk, I don't know that it really went anywhere.

These brief and isolated encounters of kindness and warmth are what Darling (2018) regarded as minor gestures of short-lived acts of welcome and civility. The actions do not translate into deep long-lasting and enduring relationships that demonstrate a commitment to the person and promote a sense of shared experience and solidarity. The welcome is thought of as a transactional and professional courtesy as opposed to an interpersonal connectedness to the community. Little or minimal effort is required in this good practice. There is no exchange of personal experiences or building of trust; only the extension of a good social practice (Darling, 2018). 


\section{2 "Culture Substance Events are Needed": Cultural Representation and Celebration}

Cultural representation and celebration were important experiences participants hoped would be integrated into the college activities. At least $83 \%$ of the participants felt the college should have done a better job with recognizing the culture and contributions that minority groups have made to society. In not doing so, they perpetuated the idea of invisibility. Lee-Bitsoi, Gordon, Harper, Saenz and Teranishi (2014) referenced the concept of (in) visibility that argues Native, African, and Hispanic American cultures have been visibly inaccurately portrayed through a Eurocentric lens. Therefore, the true picture and narrative remain invisible. Students of color need a platform to share cultural history and tell personal stories, which fosters a sense of belonging, empowerment, pride, and agency (Strayhorn, 2012; Kuh, Kinzie \& Schuh, 2010). Participants felt this was an opportunity for the college to learn from other cultures, celebrate their music, food, rituals, and foster a sense of community. The males imagined that cultural representation and celebration would demonstrate an institutional commitment to the social and psychological well-being of all students in addition to understanding how to meet the unique needs of men of color.

Comments made by participants:

- HF3 \& NF2: Culture substance events are needed. I think it's good to have those different cultural backgrounds so that way everybody just kinda learns a little bit about other things, other cultures and things because, see, you got Native Americans, it's like the diversity council that has one Asian person and six Caucasians; and you got a Caucasian trying to tell a Native American his background.

- NAGRAD5: I think they could have found other men of color, to be present, especially at orientation when you first came in, or when you first became a part of the school. I think they could've had different outreach programs, such as we have the Leopocha clinic here in town, which is for the Native Americans.

Some of the males offered recommendations on how cultural appreciation and representation could be demonstrated through various activities. The objective was to be provided the opportunity and platform to share insight into their background and experiences, which could be done through simple activities such as sharing of cultural food dishes or traditional holiday celebrations. These actions would serve two purposes. First, the men would feel respected, acknowledged, and visible to the college community. Secondly, the institution could gain vital insight and knowledge into this population of students, thereby gaining a greater appreciation for their plight as individuals and a collective.

Comments made by participants:

- HF3: Yeah, it's going to sound funny, but you can do it through food. You can have some dinner, or something that involves food. This is my country. Regardless if you're black, Asian, whatever, if you come to my house, I will offer something to eat. With food you start breaking barriers. You have the food and then you start knowing that person and you start sharing the food, and when you're sharing the food you make conversations, and then you start knowing that person.

- HF3: This past holiday season I brought one of my friends to this annual New Year's Filipino party that's here. There's a large community of Filipino people here, surprisingly. I brought one of my friends, and she was totally weirded out. She was like, "I am so uncomfortable. This is weird." I was like, "It's normal." Just the music. The way people were acting. The food. She'd never seen that before. She was like, "I just feel like I wasn't in Montana." But she thought it was pretty cool. She was the minority.

The participants were aware of the limited internal cultural capacity of the college. The hope was that the institution would foster collaborative relationships and partnerships with the surrounding communities to help inform policies and practices designed to engage a culturally diverse student population. Collaborations could entail working with community leaders, local churches, YMCAs, Tribal Nations, Tribal College and University (TCU), Historically Black Colleges and Universities (HBCU) and Hispanic Serving Institutions (HSI). Building these types of alliances would assist in the development of an accurate portrayal of students of color and establish a network of support which is essential to belonging (Harper \& Harris, 2010). While all of the males made the choice to attend college, often the decision came with some hesitation and sacrifice which left a gap in support. Additional assistance was needed to fill the emotional, financial, and mental support void.

Comment made by participant:

- NAGRAD5: To leave the reservation ... first, I think you are trained the opposite of the little train. Instead of saying, "I think I can," everybody tells you, "No you can't. No, you can't." So I think it is really hard to get out of there. I think the family ties, nobody else leaves, so it's hard to be the first one to leave. Then of course, all the self-doubt, you get ready to leave and people try to pull you back in and say, "No, you don't really want to do that." 
Because if you go, and start seeing those who stayed start feeling even worse. It doesn't give hope, it actually makes them more discouraged.

Participants stated that providing cultural representation and celebration would establish a sense of support and community. Some of the male isolated themselves from the broader college community because of instances of microaggression received from both faculty and staff. Additionally, the males felt an overwhelming pressure of the weight of their entire race on their shoulders, so they had to behave a certain way. Sponsoring events that celebrate their culture and connect them to others of similar backgrounds and experiences would ease some of that anxiety.

\section{3 "We are Here" Cultural Competency and Humility Education}

Cultural competency and humility education was a major theme that influenced the experience and student perception of the institution. Participants reported several examples of micro aggressive behavior, acts of exclusion, micro invalidation, and insensitivity, which resulted in a conscious disengagement and isolation from the campus community. All the males could recall a moment or perceived experience of racism at the institution by an instructor, student, or staff member. These incidents were ignored or not reported, in fear of being labeled a troublemaker or a conditioned response as a person of color to brush off these types of acts. One of the males discusses navigating his multicultural identity of being Native American and White.

Comment made by participant:

NAF1: I was told I got the best of both worlds because I'm a tribal member but I look like a Wasi'chu (people of European descent) so I don't have some of the struggles of my friends. I hear comments about, "Indians get everything for free." They got free hospital care and scholarships. Why did the Indians get free college? Some of the stereotypical stuff you hear about Indians, I just basically ignore and keep going.

Participants felt that cultural competency should translate into behaviors, attitudes, systems, and policies all at the institutional and individual level to create a healthy and interactive atmosphere. Additionally, cultural humility should be self-reflective and a committed practice that challenges one's cultural bias with the understanding that it is impossible to know everything about other cultures, so learning is a lifelong process. The approach should always be explored with humility and respect for others. Training should not be a one-time activity, but an ongoing practice that is permanently integrated into the hiring on-boarding process for both faculty and staff. Exposure and exploration of diversity was suggested for students in and out of the classroom.

Comments made by participants:

- HF6: I want them to understand that everybody is different. Even white males, they are all different, they have different things in their head and, yeah, men of color, we have different things in our minds because we came from a different culture, and by that you have different beliefs, religion issues that need to be respected somehow in a way that they feel welcoming.

- HF6: No, I won't feel comfortable sharing my culture because of the political environment. You have this political system now that if you have an accent and somebody asks you directly where you're from there is no way, no way you're going to tell them where you're from because you don't know their intentions, regardless whatever situation.

Postsecondary institutions possessing a comprehensive understanding of the background and experiences of men of color, especially those students who may be facing immigration issues, is critical to cultural competence and humility. Lack of trust in faculty or staff members with nuanced and sensitive information can prevent students from reaching out for support when challenges are encountered. Lee-Bitsoi, et al. (2014) stated, understanding the historical issues that affect student development is essential to establishing a meaningful relationship. This may include issues that directly influence men of color such as tribal cultures, masculinity, social justice, and other historical and current challenges that black and brown males have encountered over the last two years. The male experienced a "double consciousness" which is the self-being torn between two conflicting identities that resides in one shaded body. Self-worth was measured by the standards of a white society, so balance had to be found in navigating a white college environment, while maintaining pride in their racial and ethnic identity. The factor of competency and humility was of great importance for Native American students as it demonstrated a sign of respect, recognition, and reciprocity as many institutions are built on land owned by indigenous people. Acknowledgment of their indigenous identity and the relevance of their contribution to the higher educational system are important to student success (Lee-Bitsoi, et al., 2104). Though there were a small number of males of color enrolled in the College, the participants felt it necessary the institution make intentional efforts to recognize their presence. 
Comment made by participant:

- HF2: We are here, even though there is a small percentage of us here... we are here. We do ... I don't know if we would need different ways of treatment, or more excessive help. But we are not going anywhere.

\section{Discussion and Implications}

Our study explored and unpacked the social and academic factors that influenced and contributed to creating a sense of belonging for men of color attending a 2-year PWI. Additionally, what perceived institutional practices and individual behaviors contributed to fostering an environment where participants felt like they mattered? The findings suggest that participants felt the institution did a good job of inviting and welcoming the males into the college environment, but neglected to provide relevant services, cultural programming, and platforms that validated, supported, acknowledged, and respected their identities (Strayhorn, 2012). The presence of these factors created a profound distinction and difference between fostering a sense of belonging and extending an invitation of welcome.

Previous research has focused on the concept of "sense of belonging" and its impact on student retention and persistence and graduation, particularly, students of color who are underrepresented and often underserved in the college environment. The perceived belief of being a valued member of the campus community, mattering, respected, accepted, and valued team member plays a key role in student development and agency, particularly for men of color. Cultivating this type of institutional culture, first requires a comprehensive understanding of the meaning and difference between creating an environment of welcoming or belonging and how to operationalize those behaviors and practices to generate the desired outcome. Welcoming students into the college environment does not equate to creating a sense of belonging. The study revealed that several institutional actions should be integrated into policy and practice (a) experience an atmosphere of welcome, (b) desire for cultural representation and celebration (c) and the importance of DEI training to develop cultural competence and humility. These actions need to be continuous and intentional to be considered genuine efforts.

Many US colleges and universities, both two and four-year, host some form of welcome activities for first year and returning students (Rudisille, Stringer \& Thiebe, 2012). Welcome week or week of welcome (WOW) typically occurs during the first week of the semester with the intended purpose of introducing new students to the opportunities and services provided by the institution in addition to creating a social, interactive, and fun experience (Rudisille, Stringer \& Thiebe, 2012). After this week, students are left to navigate the institution and establish a sense of community on their own. This can be challenging for men of color for two reasons. If you are a student of color and do not see representation or a mirror image of yourself, fostering meaningful connections can be difficult. Also, research has shown that a large percentage of students of color who enrolled in college, identify as first-generation, which means they may not know how to effectively navigate the college environment.

The broader implication for this study is that PWI two-year colleges need to examine how they define and operationalize the definition of sense of belonging. Current actions demonstrate creating a sense of welcome for men of color does not translate into creating an environment that demonstrates cultural sensitivity, empathy, and validation that is inclusive of their background and experiences. Hableyl, Bloom, and Robbins (2012) argued the experience and transition into a college environment cannot be viewed as a one-time activity, such as an orientation event, but should be understood as a process that is developed and nurtured over time. The reality is that men of color (MOC) are often first-generation students, from underserved neighborhoods, Pell-grant eligible, working 20-30 hours a week, bearing family responsibilities, and possibly underprepared for the college environment.

Overall, the experiences of MOC attending community colleges are different from the traditional-aged students who are recent high school graduates, possibly leaving home for the first time. As such, social and academic programming should include their voices and opinions in the design and implementation. Due to limitations on time and life demands, support services, and activities need to occur during nontraditional times, such as amid classroom time, after business hours, weekends or online. Historically, post-secondary institution focus has been on traditional students, which can be problematic for nontraditional students. A proactive approach should be taken to conduct outreach to MOC to build relationships, foster trust, solicit input, generate early alerts, and construct effective interventions. Also, this can serve as a great opportunity to learn about their culture, background, experiences, challenges, and opportunities, which can inform institutional practice. Additionally, the males can serve as a liaison between the college, and their community, while mentoring incoming students of color (Harper \& Harris, 2010). 


\section{Limitations}

In this study three significant limitations included the single site research location, sample size, and the affiliation of the Principal Investigator current role as the coordinator for men of color initiatives. However, the aim was to offer an in-depth and robust understanding of creating a sense of welcome as opposed to belonging for men of color who attended a predominantly white 2-year college. Researchers should continue to investigate how Tribal Colleges and Universities (TCU), Historically Black Colleges and Universities (HBCUs) and Hispanic Serving institutions (HSI), and other Minority Serving Institutions (MSI) address this issue of belonging to determine if a collaboration between PWIs and MSIs could result in better outcomes.

\section{Conclusion}

According to the American Council on Education (2020), the changing landscape of higher education is due to an increasingly more racially diverse and educated US population. Consequently, current institutional practices, processes, artifacts, and traditions must adjust and operate differently to promote inclusivity for students of color (Parker, 2019). Students now, more than ever, are acutely aware of the unwelcoming environment created by some higher educational institutions due to the campus racial and diversity climate (Parker, 2019). Growing acts of cultural insensitivity and discriminatory incidents on college campuses around the country have increased the negative perceptions that students have about campus culture, leadership, and belonging.

The males in this study were conscious and hypersensitive to the impact societal influences have on the college culture. These issues of educational inequities, academic disparities, marginalization, mistreatment, micro aggression, and invalidation disproportionately affect men of color attending predominantly white 2-year colleges. Protests in both the US and around the world are demanding equity, access to life, liberty, and the pursuit of happiness. Human rights that symbolize the American dream. There should be an increased awareness and commitment to creating a sense of belonging for all students, no matter their gender, ethnicity, race, political affiliation, religious beliefs, sexual orientation, or cultural background. Awareness and empathy become more important to historically racialized, marginalized, and underrepresented populations of students.

College campuses must construct intentional and ongoing efforts that address the specific needs of men of color attending predominantly white 2-year institutions, whose experience differ from White males and women. These efforts should be supported and underpinned by sound research on race, diversity, student development, antiracism, and gender identity. Unlike creating an environment of welcoming, which is rooted in tolerance and social obligation, colleges need to advance past establishing communities of welcome, to foster a sense of belonging for men of color. Understanding these nuanced and complex real-life realities associated with race, ethnicity, culture, and gender will assist institutions in constructing solutions that address the specific and dire issues these males encounter. As participant HF6 boldly stated, "we are here and not going anywhere".

\section{References}

American Council on Education. (2020). Race and Ethnicity in Higher Education. Retrieved from https://www.equityinhighered.org/

Arum, R., \& Roksa, J. (2011). Academically Adrift: Limited Learning on College Campuses. University of Chicago Press. https://doi.org/10.7208/chicago/9780226028576.001.0001

Bailey, T., Jaggars, S., \& Jenkins, D. (2015). Redesigning America's Community Colleges: A Clearer Path to Student Success. Harvard University Press. https://doi.org/10.1177/0091552115606519

Banks, T., \& Dohy, J. (2019, January). Mitigating Barriers to Persistence: A Review of Efforts to Improve Retention and Graduation Rates for Students of Color in Higher Education. Higher Education Studies, 9(1), 118-131. https://doi.org/10.5539/hes.v9n1p118

Briscoe, K. L., Jones, V. A., \& Hatch-Tocaimaza, D. K. (2020). Positionality and Power: The Individual's Role in Directing Community College Men of Color Initiatives. Journal of Student Affairs Research and Practice, 57(5), 473-486. https://doi.org/10.1080/19496591.2019.1699103

Campbell-Whatley, G. D., Wang, C., \& Toms, O. (2015). Factors Affecting Campus Climate: Creating a Welcoming Environment. New Waves Educational Research \& Development, 18(2), 40-52.

Camputaro, J. (2018). The Role of College Unions in Developing Students' Sense of Community. Association of College Unions International. Retrieved from https://www.acui.org/resources/bulletin/bulletin-detail/2018/1 1/30/the-role-of-college-unions-in-developing-students-sense-of-community

Creswell, J. W. (2007). Qualitative inquiry and research design: Choosing among five approaches (2nd ed.). Sage publication. 
Darling, J. (2018). The fragility of welcome-commentary to Gill. Fennia-International Journal of Geography, 196(2), 220-224. https://doi.org/10.11143/fennia.75756

Felix, E. R., \& Gonzalez, Á. (2020). Using Institutional Planning to Support Men of Color in Community College. Community College Journal of Research and Practice, 1-15. https://doi.org/10.1080/10668926.2020.1841043

Grawe, N. (2021). How to survive the enrollment burst. Chronicle of Higher Education, 67(10), 11-16.

Guillory, R. M., \& Wolverton, M. (2008). It's about family: Native American student persistence in higher education. The Journal of Higher Education, 79(1), 58-87. https://doi.org/10.1353/jhe.2008.0001

Habley, W. R., Bloom, J. L., \& Robbins, S. (2012). Increasing Persistence: Research-based Strategies for College Student Success (1st ed.). Jossey-Bass. https://doi.org/10.1353/csd.2014.0028

Harper, S. R., \& Harris, F. (2010). College men and masculinities: Theory, research, and implications for practice. San Francisco: Jossey-Bass.

Harris, F., \& Wood, J. L. (2013). Student success for Men of Color in Community Colleges: A review of published literature and research, 1998-2012. Journal of Diversity in Higher Education, 6(3), 174-185. https://doi.org/10.1037/a0034224

Hunter, M. S. (2006). Fostering Student Learning and Success through First-Year Programs. Association of American Colleges and Universities, 8(3), 1-6.

Institute for Higher Education Policy. (2013). Supporting Men of Color Along the Educational Pipeline: Research and Practice. Retrieved from http://www.ihep.org/research/publications/supporting-men-color-a long-educational-pipeline-research-and-practice

Kniess, D., Buschlen, E., \& Chang, T. (2020). Men of Color Transitioning to College: The Case for Community Assets, Community Programs, and Social Capital. Journal of At-Risk Issues, 23(1), 36-45.

Kuh, G., Ikenberry, S., \& Jankowski, N. (2015). Using Evidence of Student Learning to Improve Higher Education (Jossey-bass Higher and Adult Education. Jossey-Bass Publishing.

Kuh, G., Kinzie, J. \& Schuh, J. (2010). Student Success in College: Creating Conditions That Matter. Jossey-Bass Publishing.

Lee-Bitsoi, L., Gordon, E. T., Harper, S. R., Saenz, V. B., \& Teranishi, R. T. (2014). Men of Color in Higher Education: New Foundations for Developing Models for Success. Stylus Publishing.

Lee, J., \& Ransom, T. (2011). The Educational Experience of Young Men of Color: A Review of Research, Pathways and Progress. College Board Advocacy \& Policy Center. Retrieved from https://files.eric.ed.gov/fulltext/ED521425.pdf

Maestas, R., Vaquera, G. S., \& Zehr, L. M. (2007). Factors impacting sense of belonging at a Hispanic-serving institution. Journal of Hispanic Higher Education, 6(30), 237-256. https://doi.org/10.1177/1538192707302801

Museus, S. D., Varaxy, Y., \& Natasha, S. (2018). How Culturally Engaging Campus Environments? Influence Sense of Belonging in College: An Examination of Differences between White Students and Students of Color. Journal of Diversity in Higher Education, 11(4), 467-483. https://doi.org/10.1037/dhe0000069

National Center for Education Statistics. (2019). Digest of National Education Statistics. Retrieved from https://nces.ed.gov/programs/digest/d19/tables/dt19_326.20.asp

Parker, E. T. (2019). Structuring Diversity: Chief Diversity Offices as structural responses to a cultural issue. Journal for the Study of Postsecondary and Tertiary Education, 4, 263-277. https://doi.org/10.28945/4433

Platt, C., Holloman, D., \& Watson, L. (2015). Boyhood to Manhood. New York, NY: Peter Lang Publishing. https://doi.org/10.3726/978-1-4539-1445-8

Postsecondary National Policy Institute. (2019). Men of Color in Higher Education. Retrieved from https://pnpi.org/men-of-color/

Rudisille, J., Stringer, E., \& Thiebe, G. (2012). A Look at Welcome Week: The Role of College Unions and Student Activities in Welcoming Students. Association of College Unions International (NJ1).

Seidman, A. (2012). College Student Retention (2nd ed.). Lanham, Maryland: Rowman \& Littlefield.

Strayhorn, T. L. (2012). College Students' Sense of Belonging. New York, NY: Routledge. 
https://doi.org/10.4324/9781315297293

Weiston-Serdan, T., \& Sánchez, B. (2017). Critical Mentoring: A Practical Guide. Stylus Publishing.

Wood, J., \& Harris, F. (2013). The Community College Survey of Men: An Initial Validation of the Instrument's Non-Cognitive Outcomes Construct. Community College Journal of Research and Practice, 37, 333-338. https://doi.org/10.1080/10668926.2012.754733

\section{Copyrights}

Copyright for this article is retained by the author(s), with first publication rights granted to the journal.

This is an open-access article distributed under the terms and conditions of the Creative Commons Attribution license (http://creativecommons.org/licenses/by/4.0/). 